\title{
RAZÕES DE UM DESCONFORTO: NOTAS A PROPÓSITO DE DOIS ARTIGOS SOBRE POESIA BRASILEIRA CONTEMPORÂNEA E TRADIÇÃO
}

\author{
REASONS FOR DISCONFORT: NOTES REGARDING TWO ARTICLES ABOUT \\ BRAZILIAN CONTEMPORARY POETRY AND TRADITION
}

Solange Fiuza Cardoso YOKOZAWA ${ }^{79}$

\begin{abstract}
RESUMO: Proponho retomar e problematizar alguns dos critérios de valor usados para examinar a relação entre poesia brasileira contemporânea e tradição presentes nos artigos "Condenados à tradição: o que fizeram com a poesia brasileira", de Iumna Maria Simon, e "Negativo e ornamental: um poema de Carlito Azevedo em seus problemas", da mesma autora em parceria com Vinícius Dantas.

PALAVRAS-CHAVE: Poesia contemporânea; Poesia brasileira; Crítica; Tradição.

ABSTRACT: I propose to go back and discuss same of the judgements used to examine the conection between Brasilian contemporany poetry and tradition present in the articles "Condenados à tradição: o que fizeram com a poesia brasileira", by Iumna Maria Simon, and "Negativo e ornamental: um poema de Carlito Azevedo em seus problemas”, by Iumna Simon and Vinicius Dantas.
\end{abstract}

KEYWORDS: Contemporany poetry; Brazilian poetry; Criticism; Tradition.

Como leitora interessada em entender o modo de ser e estar da poesia brasileira na contemporaneidade, acompanho com interesse não apenas essa poesia, mas também as construções críticas sobre ela. Tais construções, que representam olhares diversos, muitas vezes conflitantes, que trazem os titubeios, as incertezas, a nebulosidade de um pensamento que está se fazendo sobre um objeto em processo, às vezes, dizem mais sobre o lugar da crítica e do crítico do que propriamente sobre o objeto examinado. Malgrado a diversidade e as divergências dos discursos críticos, eles são atravessados, central ou colateralmente, por uma mesma questão: a relação da recente escrita poética com o passado literário.

79 Programa de Pós-Graduação em Letras e Linguística, Faculdade de Letras, Universidade Federal de Goiás (UFG), CEP 74001-970, Goiânia, GO, Brasil, solfiuza@hotmail.com 
Nos últimos tempos, dois artigos que se debruçaram sobre essa questão deram o que falar. Refiro-me ao "Condenados à tradição: o que fizeram com a poesia brasileira", de Iumna Maria Simon, e "Negativo e ornamental: um poema de Carlito Azevedo em seus problemas", de Iumna Simon e Vinícius Dantas, ambos de 2011, publicados, respectivamente, na revista Piauí e nos Novos Estudos CEBRAP. São trabalhos que, em lugar de surpreender, antes reiteram o ponto de vista que vem sendo formulado pelos autores individualmente ou conjuntamente, em vários outros ensaios, como "Poesia ruim, sociedade pior" (DANTAS, SIMON, 1985), "A nova poesia brasileira e a poesia" (DANTAS, 1986), "Considerações sobre a poesia brasileira em fim de século" (SIMON, 1999) e "Situação de sítio" (SIMON, 2008). Segundo esse ponto de vista, emblemático de um dos modos correntes de se ler a contemporaneidade poética brasileira, esta se apresenta como um esvaziamento, uma degradação de linhas de força da alta modernidade.

Os artigos de 2011 me foram generosamente enviados por Paulo Franchetti assim que publicados, acompanhados de breves mensagens solicitando minha opinião sobre eles. Também Elaine Cintra, quando estive na Universidade Federal de Uberlândia para participar do Simpósio Internacional de Letras e Linguística (2011), pediu-me parecer sobre o "Condenados à tradição: o que fizeram com a poesia brasileira". Não me lembro ao certo o que respondi a Elaine Cintra e a Paulo Franchetti, mas confesso que esses trabalhos me causaram um misto de respeito, pela reflexão densa que realizam sobre a recente poesia brasileira, numa postura avessa tanto à valorização euforizante e indiscriminada dessa poesia quanto à sua condenação sem justificativa, e desconforto, pelo fato de me parecerem questionáveis alguns dos critérios de valor acionados. Este texto é, pois, uma tentativa de entender as razões desse desconforto e de melhor formular o meu entendimento sobre os artigos.

No ensaio "Condenados à tradição: o que fizeram com a poesia brasileira", Iumna Simon observa que a questão da tradição se tornou fulcral para a poesia brasileira que vem sendo produzida a partir dos anos 80 . Mas, segundo a ensaísta, "o que se busca na tradição não é nem o passado como experiência, nem a superação crítica do seu legado." Diferentemente de Eliot (s.d.), para quem a tradição não se herda, mas se conquista com árduo trabalho, para quem não só o presente é dirigido pelo passado, mas este, se verdadeiramente presente, é reorganizado por aquele, Simon entende que, na poesia brasileira contemporânea, haveria uma "apoteose pluralista" da tradição, uma 
"ideia inespecífica de tradição", que seria reduzida a uma contemporaneidade de formas literárias, sem adesão à experiência histórica:

O passado, para o poeta contemporâneo, não é uma projeção de nossas expectativas, ou aquilo que reconfigura o presente. Ficou reduzido, simplesmente, à condição de materiais disponíveis, a um conjunto de técnicas, procedimentos, temas, ângulos, mitologias, que podem ser repetidos, copiados e desdobrados, num presente indefinido, para durar enquanto der, se der. (SIMON, 2011).

A esse aproveitamento do passado, a autora denomina "retradicionalização frívola", expressão que vem empregando desde o final da década de $90^{80}$, e ilustra com declarações de Carlito Azevedo ${ }^{81}$ e Eucanaã Ferraz ${ }^{82}$, nas quais evidencia, não sem razão, uma recusa simplificadora da tradição moderna da ruptura e um entendimento equivocado dessa tradição, como também delas depreende uma visão estática, museológica do passado, que não parece mais incompleto, nem precisa ser

80 O termo "retradicionalização" já aparece no ensaio "Considerações sobre a poesia brasileira em fim de século" (SIMON, 1999).

81 Carlito Azevedo: "Eu sou absolutamente tradicional. Até os anos 50, com as vanguardas, com a ideia de poesia concreta, existia a ideia de que era legal romper com a tradição. Este é o lado do modernismo e das vanguardas com que menos me identifico. Acho mais ousado estar dentro da tradição do que tentar criar do lado de fora. É mais ousado quem tenta dialogar com uma tradição enorme, pois terá que se medir com grandes criadores. Quando um autor escreve hoje um soneto, ele terá que se medir com Dante, com Camões, com Shakespeare. É essa uma ousadia muito maior do que partir para um campo novo em que não há um adversário. Gosto muito de saber que tenho uma família no tempo e no espaço, com a qual dialogo constantemente... Sou herdeiro do concretismo como sou do modernismo, da poesia marginal e do surrealismo, pois, tendo vindo depois deles, não ignorei o legado de nenhum." (Entrevista ao Jornal do Brasil, de 14 de dezembro de 1996, reproduzida em "Condenados à tradição: o que fizeram com a poesia brasileira")

82Eucanaã Ferraz: "Quanto à possível caracterização da poesia que se escreve hoje no Brasil, há um ponto pacífico: estamos diante de uma extraordinária heterogeneidade. Na convivência de linhagens está em cena, sobretudo, uma contemporaneidade de "formas". Assim, o verso livre convive com o metro; o soneto com a página neoconcretista; o coloquial com o registro culto e elevado, assim por diante. Essa atualização de formas várias mostra o quanto os poetas atuais não optaram por uma linguagem canônica, inquestionável, com a qual ingressariam sem riscos e pré-aprovados no quadro da poesia brasileira... Hoje, diante do acervo da poesia brasileira e mesmo universal, os poetas sentem-se beneficiados; têm liberdade de fazer uso de quaisquer formas, numa relação positiva, num exercício de discernimento que implica a aceitação de certos paradigmas e a negação de outros, mas sem que uma verdade canônica estabeleça o certo e o errado para todos." (Entrevista de 2002, no site do poeta, reproduzida em "Condenados à tradição: o que fizeram com a poesia brasileira") 
transformado, mas é aproveitado de modo acrítico e indiscriminado, reduzindo-se à existência simultânea de formas ${ }^{83}$.

A retradicionalização nasceria, segundo Simon, como reação à desqualificação formal e à baixa mímesis a que os poetas marginais haviam submetido a poesia brasileira nos anos 1970 e estaria ligada à saída de cena, do campo literário, da referência nacional, que se constitui como um critério de valor, sobretudo, para os românticos, em seu desejo de construir uma tradição nacional, e também para os modernistas, em seu projeto de internacionalização da literatura brasileira por meio da expressão de um contingente original e nacional de cultura. Central para a literatura romântica e modernista em sua narrativa da identidade brasileira, mas ainda baliza do itinerário concretista, a referência nacional seria desmanchada pela poesia contemporânea:

A tradição, que passou a ter o mesmo valor de um artigo de comércio, já não representa uma experiência nacional e popular em curso, ou um fator decisivo para se pensar e combater a dependência. Sem desenvolvimento ou integração nacional à vista, num quadro em que o atraso educacional e mesmo a alfabetização parecem agravados pela entrada maciça da tecnologia no cotidiano, os poetas não deixam de ter motivos para mandar às favas a responsabilidade esclarecida e crítica. Essa mudança de perspectiva, de alcance geral, convenceu os produtores culturais de que as diferenças nacionais existem como marcas de fábrica e as tradições estrangeiras são todas elas acessíveis, como se a globalização por si só franqueasse a igualdade dos processos culturais. (SIMON, 2011. Destaques meus).

Se a saída de cena, do campo literário, da referência nacional, coincide com a "retradicionalização frívola" é porque o nacionalismo constitui, para a articulista, uma salvaguarda da retomada crítica do passado literário e, por conseguinte, da validade estética de uma obra.

Parece haver um equívoco hábil e desnecessário na relação proposta por Simon entre rarefação da referência nacional e aproveitamento acrítico da tradição. Equívoco

83 Não caberia fazer restrições ao ensaio de Simon por ele ter sido desenvolvido a partir de entrevistas dos poetas, esses fabuladores profissionais. As entrevistas concedidas por poetas constituem um material crítico tão válido quanto qualquer outro, o qual, é claro, também deve ser relativizado como qualquer outro. É verdade que a crítica desenvolvida por poetas precisa ser confrontada com as suas obras poéticas, testada em relação a estas, quando, não raro, evidenciam-se fraturas, incoerências. É verdade também que só o exame atento da poesia pode dizer de sua relação efetiva com o passado, mas isso Iumna Simon levará adiante em "Negativo e ornamental: um poema de Carlito Azevedo em seus problemas", trabalho escrito em pareceria com Vinícius Dantas e que pode ser lido como um desdobramento, um desenvolvimento do "Condenados à tradição". 
porque, se é verdade que o nacionalismo não constitui mais uma linha de força da poesia contemporânea, se ele não está na pauta das discussões críticas dos poetas, não parece acertado dizer que a "experiência nacional" esteja ausente dessa poesia. Ela comparece de modo rarefeito, implícito, "enviesado" ${ }^{84}$ em algumas escritas poéticas, como em Carlito Azevedo, Orides Fontela e Cláudia Roquette-Pinto, mas não se pode esquecer que a liricização do cotidiano, em que os modernistas encontraram uma das configurações do nacionalismo, continua uma vertente forte de várias escritas do presente, um modo de elas serem e estarem na história, não obstante esvaziado de um projeto programático de Brasil. Hábil porque a restrição feita à poesia contemporânea pela crítica parece implicar a afirmação de um determinado modo de ler a literatura, para o qual a "experiência nacional" se apresenta como critério determinante. Assim, circunscrever as possibilidades da mímesis poética ao campo nacional ou a determinados aspectos da realidade brasileira, para além de um reducionismo quanto às possibilidades de representação lírica, pode significar a defesa de uma preferência crítica. Mas essa defesa talvez seja desnecessária, uma vez que, se o nacionalismo deixou de importar aos poetas, o pensar o país, a conjuntura social e econômica do Brasil e do mundo globalizado continua central para a crítica literária de base materialista a que se filia Simon e a que devemos, inclusive, densas análises que evidenciam a dimensão social de poetas contemporâneos autorreferenciais ou que não fazem referência explícita ao concreto.

A tese do imbricamento entre retradicionalização e fuga do enfrentamento do real (lê-se certo real nacional), já proposta no artigo "Situação de sítio" (SIMON, 2008), é desenvolvida em "Negativo e ornamental: um poema de Carlito Azevedo em seus problemas", trabalho escrito por Simon em parceria com Vinícius Dantas. Nesse trabalho, os autores procuram demonstrar, por meio de um minucioso e bem enunciado comentário das estratégias compositivas do poema "Na noite física" 85 , de Carlito

84 Termo empregado por Iumna Simon $(2008$, p.144) para falar do retorno do real na poesia brasileira contemporânea, quando analisa o poema "Sítio", de Cláudia Roquette-Pinto: "Talvez seja o caso de ressaltarmos na solução poética de "Sítio" a ousadia de uma técnica um tanto enviesada, mas eficaz, de encostar na vida" (destaques meus).

85 "Na noite física"

(desentranhado de um poema

de Charles Peixoto)

A luz do quarto apagada,/na escuridão se destaca/a insônia que nos atraca,/dois gêmeos na bolsa d'água.//Ao despertar levo as marcas/que de noite rabiscavas/em minha pele com a sarna/ávida de tua raiva?//E em você a cega trama/algum mal pôde? ou maltrata/ainda, que penetrava/concha, espádua, gar- 
Azevedo, a relação entre desrealização poética e "releitura pluralista e acomodatícia da tradição". Partindo desse poema de Carlito Azevedo, explicitamente desentranhado de um símile de um poema do marginal Charles Peixoto ${ }^{86}$, os autores procuram evidenciar como o poema, tomando como fonte um texto de dicção modernista fundado num registro simples, quase imediato, ancora-se em procedimentos de indeterminação sintática, em uma série desrealizante de metáforas que torna rarefeito o objeto representado, resultando em uma "irrealidade do significado" (SIMON, DANTAS, 2011, p.115).

Essa "irrealidade do significado" seria resultado de uma "leitura pluralista e acomodatícia da tradição":

Poesia marginal, Drummond, maneirismo, decadentismo, neobarroco, surrealismo, Cabral - todas essas referências estão comprimidas de tal modo que ganhem indeterminação e cada uma delas se perca numa textualidade afetadamente estetizada, nefelibata quase diríamos, sugerindo que não há evolução de formas e o pluralismo é vitorioso. (SIMON, DANTAS, 2011, p.116-117. Destaques meus).

Esse projeto poético de Carlito Azevedo nasceria da tentativa, qualificada pelos críticos de "esforço notável" (SIMON, DANTAS, 2011, p.117), de desenfantilizar o estado atual da poesia brasileira, que rebaixou a complexidade do poético a meros jogos linguísticos, trocadilhos, paronomásias, e encontrou na obra de Paulo Leminski a sua realização máxima.

Ao longo do artigo, para caracterizarem a poesia carlitiana, os críticos, além de expressões como "irrealidade do significado", "textualidade afetadamente estetizada", quase "nefeliba", já citadas neste trabalho, lançam mão de outras similares, como “indeterminação da sintaxe" (SIMON, DANTAS, 2011, p.113), "hermetismo de circunstância" (SIMON, DANTAS, 2011, p.117), "metaforização desrealizante" (SIMON, DANTAS, 2011, p.118). Ora, essas expressões evocam o jargão usado pela

galhada?//E em nosso rosto essa raia/aberta? que estranha lava/é essa que, rubra (baba/de algum diabo?), se espalha?//A luz do quarto apagada,/na escuridão se destaca/a fúria que nos atraca,/dois gêmeos na bolsa d'água.(AZEVEDO, 1996, p. 46. Destaques meus)

86 são duas e meia da manhã/a vizinha fuma um cigarro na janela/eu também/ela tem sessenta e sete anos e muitos filhos/eu trinta e cinco e apenas um/ela vive uma vida regrada/eu desregularmente insana/a insônia porém nos atraca como dois gêmeos na bolsa dágua (PEIXOTO 1985, p. 104. Destaques meus) 
crítica de base formalista para caracterizar uma linha de tradição da poesia moderna cujo paradigma teria sido definido por Mallarmé. Hugo Friedrich (1991), por exemplo, em obra que difundiu um modo de ler essa poesia, hoje relativizado, ao descrever a lírica de Marllarmé, vale-se de expressões como "aniquilamento da realidade e das ordens normais" (FRIEDRICH, 1991, p.95), “desrealização” (FRIEDRICH, 1991, p.99), "desconcretização" (FRIEDRICH, 1991, p.105) e outras tais que. Não casualmente, o poeta francês é aludido duas vezes por Simon e Dantas ao considerarem a poesia de Carlito Azevedo. Em uma dessas alusões, para caracterizarem o itinerário poético azevediano, referem-se à "trajetória rigorosa do mallarmeísmo pompier" (SIMON, DANTAS, 2011, p.119. Nota de rodapé).

Curioso como tanto a crítica de orientação formalista (a literatura não fala do mundo, mas apenas dela mesma) quanto a crítica de Simon e Dantas, calcada na relação entre poesia e experiência (a literatura deve falar da vida), por caminhos diversos, chegam, nesse caso, ao mesmo lugar ${ }^{87}$.

Assim como o processo de desrealização em Mallarmé implica, não um banimento da realidade, mas um modo de representá-la que recusa o projeto realista do século XIX e se funda na sugestão e na indeterminação, o esteticismo de certa poesia contemporânea talvez não devesse ser reduzido a uma poesia intransitiva, fogueira ardendo por si, cujo espetáculo estaria na própria combustão. Esse modo de ler Carlito Azevedo e, por extensão, alguns de seus pares, consiste na continuação de um modo já antigo de ler Mallarmé e poéticas afins e integra um consenso de leitura que há algum tempo vem sendo revisto.

Para fechar as considerações sobre o artigo de Simon e Dantas, vale observar que nem todas as fontes que os autores encontram para o poema de Carlito Azevedo e que seriam a prova do seu aproveitamento indiscriminado do passado literário são diretamente sugeridas pelo poema, como é o caso do maneirismo, decadentismo e neobarroco, influências que ficam carecendo de maiores esclarecimentos por parte dos articulistas. Logo, estes talvez lancem mão de uma criatividade borgesiana para identificar as fontes do poema.

87 Não se pode desconsiderar a importante contribuição da crítica materialista, sobretudo de fundamento adorniano, na ressignificação da dimensão social da obra de poetas de filiação romântico-simbolista. Mas o comentário leva em consideração o que está enunciado no artigo de Simon e Dantas. 
A referência borgesiana diz respeito ao antológico "Kafka e seus precursores", em que Borges encontra uma série de textos precursores para a escrita de Kafka. São textos heterogêneos, que não se parecem entre si, mas nos quais Borges encontra a “idiossincrasia Kafka” (BORGES, 1999, p.98). Isso é possível porque, conforme conclui Borges (1999, p.98), "cada escritor cria seus precursores. Seu trabalho modifica nossa concepção do passado, como há de modificar o futuro" (Destaque do autor). Sobre essa conclusão, tem-se destacado, frequentemente, o modo como ela subverte a antiga crítica das fontes e influências, fazendo do novo escritor o pai, o precursor, dos escritores do passado. Se isso é fato no mini-ensaio borgesiano, não menos interessante é a importância atribuída pelo autor argentino, que sempre se declarou mais leitor do que escritor, ao papel da crítica na invenção dos precursores de Kakfa. O trabalho da crítica, diante da obra considerada, não seria apenas encontrar releituras explícitas, intertextualizações de obras do passado, mas também criar fontes não pressentidas diretamente, mas plenamente justificáveis quando encontradas.

À maneira de Borges, algumas das tradições encontradas por Simon e Dantas no texto de Carlito Azevedo não decorrem de sugestões diretas, mas foram acréscimos críticos. "Descobrir" relações, confluências, entre um escritor e o passado é um exercício legítimo da crítica literária. O que não parece sê-lo é arrolar essas "influências", obtidas por meio de leituras relacionais, de inferências críticas, como dado para confirmar o ecletismo indiscriminado de um poeta.

Em "Noite física", há outra tradição recuperada de modo mais evidente que os ensaístas não nomeiam. O modo como Carlito Azevedo recupera essa tradição talvez tenha alguma coisa a dizer sobre o diálogo da recente poesia com o passado. Trata-se daquela tradição que pode ser depreendida da nota crítica que acompanha o poema entre parêntese: “(desentranhado de um poema de Charles Peixoto)". Mais do que a relação buscada e declarada do poema de Carlito Azevedo com o de Charles Peixoto, está a sua relação, pelo avesso, em clave negativa, com um poema de Manuel Bandeira. Bandeira, seguindo uma tendência da poesia moderna e modernista, escreve o seu "Poema tirado de uma notícia de jornal", explicitando que a poesia pode ser tirada de esferas não poéticas, como os meios modernos de comunicação de massa. $\mathrm{O}$ achado poético, como demonstrou David Arrigucci (1990, p.103) em leitura bastante conhecida desse poema, é também “o achado de um país, pois equivalia a um modo de tratar esteticamente uma visão do Brasil” (destaques do autor). Já não se guiando mais pelo projeto nacionalista dos modernistas, Carlito Azevedo realiza uma poesia que se reconhece desentranhada de 
outra poesia. É a literatura que, em lugar de falar da vida, fala dela mesma. A questão é que a literatura, mesmo quando fala de outros textos, também é sempre um modo de falar do mundo e do homem, independente do projeto de quem escreve, independente das declarações dos poetas.

\section{REFERÊNCIAS}

ARRIGUCCI JR., D. A poesia de Manuel Bandeira: humildade, paixão e morte. São Paulo: Cia. das Letras, 1992.

BORGES, J. L. Kafka e seus precursores. In: Obra completa. São Paulo: Globo, 1999. p. 96-98.

DANTAS, V. A nova poesia brasileira e a poesia. Novos estudos CEBRAP, São Paulo, n.16, p.40-53, dez.1986.

ELIOT, T. S. A tradição e o talento individual. In: Ensaio de doutrina crítica. Trad. Fernando de Mello Moser. /s.1./ Guimarães /s.d./ p. 21-35.

FRIEDRICH, H. Estrutura da lírica moderna. Trad. Marise M. Curioni e Dora F. da Silva. 2.ed. São Paulo: Duas cidades, 1991.

SIMON, I. M. Condenados à tradição: o que fizeram com a poesia brasileira. Piauí, n.61, out. 2011. Disponível em http://revistapiaui.estadao.com.br/edicao-61/aceleracaodo-crescimento/condenados-a-tradicao Acesso em 25 jun. 2012

Considerações sobre a poesia brasileira em fim de século. Novos Estudos CEBRAP, São Paulo, n.55, p.27-36, nov. 1999.

Situação de sítio. In: PEDROSA, C., ALVES, I. (Org.) Subjetividades em devir. Rio de Janeiro: 7Letras, 2008. p. 133-147.

DANTAS, V. Um poema de Carlito Azevedo em seus problemas. Novos estudos CEBRAP, São Paulo, n.91, p.109-120, nov. 2011.

Poesia ruim, sociedade pior. Novos estudos CEBRAP, n.12, p.48-61, jun.1985.

Artigo recebido em 31/08/2012

Aceito para publicação em 24/09/2012 